\title{
Africa: Towards comprehensive revenue data
}

Written by: Michelle Harding, OECD Centre for Tax Policy and Administration, Emmanuelle Modica, OECD Centre for Tax Policy and Administration, Sébastien Markley, OECD Development Centre and Henri-Bernard Solignac-Lecomte, OECD Development Centre

Last update: 5 April 2017

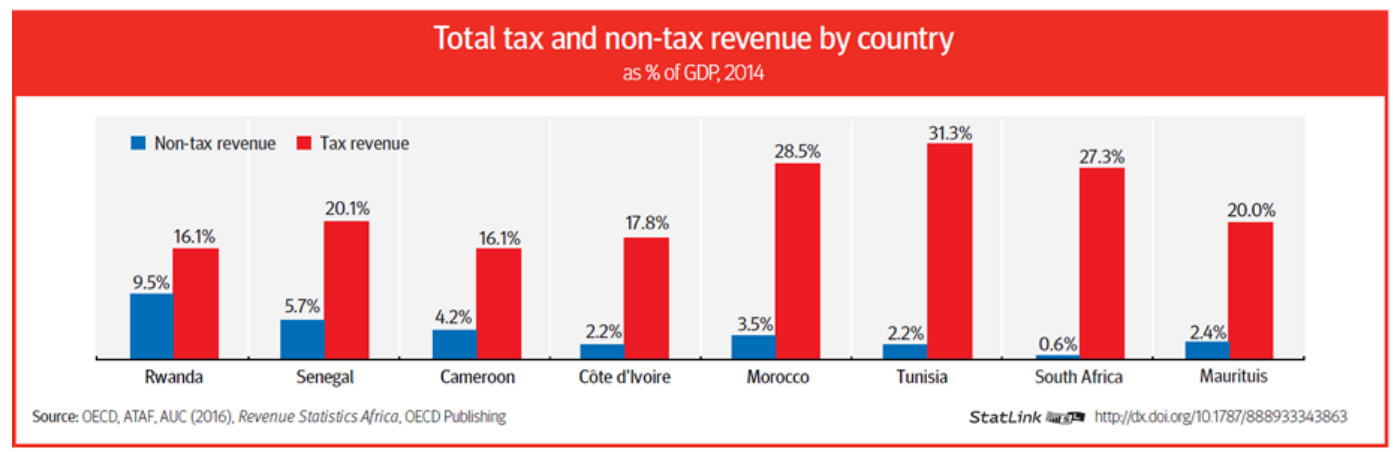

The African Union has made harmonising economic statistics across Africa a key objective of Agenda 2063, which is its 50-year pan-African economic development strategy. Better data is also relevant to the UN Sustainable Development Goals, of which goal 17 aims to improve domestic tax revenues and collection to strengthen resources.

Revenue Statistics in Africa, first published in April 2016, is a step towards the African Union's goal. It is a pan-African project that provides comprehensive and accessible revenue data for African countries. The project is made possible through a partnership between the OECD, the African Union and the African Tax Administration Forum (ATAF), with European Union support, and includes detailed data on government revenues for eight African countries: Cameroon, Côte d'Ivoire, Mauritius, Rwanda, Senegal, Morocco, South Africa and Tunisia. Future editions will cover an increasing number of African countries.

Revenue Statistics in Africa is tailored to African countries, and the needs of tax officials are at the heart of shaping the publication. Participation in the publication is free and the statistics are prepared as part of a transparent and collaborative process. This means countries and OECD statisticians work together to harmonise their data using well-established OECD classifications. This close 
co-operation ensures the accuracy and comparability of the data at a high level of detail, and allows countries to resolve common classification and data availability problems. The final statistics are readily accessible in the Revenue Statistics in Africa publication through the OECD online (http://oe.cd/1ES) and form part of the OECD's global revenue statistics covering 66 countries.

The first edition of Revenue Statistics in Africa revealed the wide divergence in African tax systems. Differences in the level, structure and volatility of revenues are notable across the eight countries included. Morocco, South Africa and Tunisia, which have the most diversified economies, displayed tax to GDP ratios ranging from $28 \%$ to $31 \%$ of GDP in 2014. In contrast, Cameroon, Côte d'Ivoire, Mauritius, Rwanda and Senegal had tax revenues between $16 \%$ and $20 \%$ of GDP. The differences between total non-tax revenues collected as a percentage of GDP were even greater: these ranged from $0.6 \%$ of GDP in South Africa to $9.5 \%$ of GDP in Rwanda, and for all countries, varied greatly from year to year. Despite these differences, all eight countries have increased their tax-to-GDP ratios since 2000, with increases of more than five percentage points recorded over this period in Morocco, Rwanda, South Africa and Tunisia. These changes resulted from a combination of tax reforms and the modernisation of tax systems and administrations.

In June 2016 experts from 20 African countries and partners met in Pretoria, South Africa, to discuss the findings from the report and how to improve further the collection and harmonisation of revenue statistics. Several new countries have expressed interest in Revenue Statistics in Africa, and the number of countries covered in the second edition is set to rise. The importance of the data in asking and answering the right questions is a highlight. For instance, what impact does the informal sector have on tax pressures and the reporting of tax expenditures? What are the reasons for different tax structures in neighbouring countries? What has the effect of tax reforms in African countries been?

The true measure of Revenue Statistics in Africa will be its influence on tax policy and, ultimately, its contribution to inclusive growth and the development goals of African countries. More analysts in African governments will need to be made aware of the data and use them for their analysis and communications with stakeholders. More user-friendly tools are being prepared to help them, such as instruction manuals, country notes and pamphlets.

Over the next few years, the aim is to continue building a network of African experts to help improve the comparability and availability of revenue data across the continent. Officials in Africa and in the rest of the world will be watching to see how these collaborative efforts can inspire new developments in tax policy, and foster positive economic and social outcomes, too. 


\section{References}

African Economic Outlook 2016 http://dx.doi.org/10.1787/aeo-2016-en

Revenue Statistics in Africa http://dx.doi.org/10.1787/9789264253308-en-fr 